\title{
4 \\ Just a jobs program? CDEP employment and community development on the NSW far south coast
}

\author{
Kirrily Jordan
}

\section{Introduction}

Discussions about Indigenous public policy often focus on remote areas. However, the role and influence of Commonwealth-funded programs like the Community Development Employment Projects (CDEP) in more densely settled Australia is no less profound. The far south coast of NSW was one of many regional areas where CDEP was closed in 2007. For some observers, the justification for this was sound: CDEP had never been intended for regional or urban locations and was not warranted because Indigenous residents of these areas lived within reach of mainstream labour markets. If CDEP was simply an employment program, it was argued, participants would do better without CDEP wages, getting support instead from mainstream employment services to find alternative jobs. It was this kind of reasoning that was used to justify many of the program changes outlined in Chapters 1 and 2. 
The story on the far south coast, however, is much more complicated than this reasoning allows. Since CDEP closed there have been some gains in mainstream employment, but they are small. The reasons why more non-CDEP employment has not eventuated are complex and warrant further investigation if policymakers are serious about wanting to improve outcomes there. Moreover, the closure of CDEP has had other consequences for Koori communities that demonstrate the much broader role that CDEP played in the region. Local residents implicate CDEP's closure in a range of ongoing concerns, including lost assets and services, closed businesses, reduced institutional capacity, fractured relationships and an enduring loss of morale. For these reasons, many Aboriginal people on the far south coast still see their communities as worse off since CDEP's decline.

This chapter investigates these concerns and the implications for future livelihoods of Aboriginal people in this region. It first briefly documents the history of CDEP in urban and regional Australia, identifying the factors that led to its expansion from 1987 and eventual decline to 2007. It focuses specifically on how CDEP was used on the NSW far south coast in this period, and the evidence of outcomes since the program's closure. The analysis suggests that defining CDEP as 'just a jobs program' was too narrow and that the social, community and economic development functions it could provide have never been adequately replaced. Moreover, the case is made that these social and community development functions were not peripheral to job outcomes but central to addressing some of the significant barriers to mainstream work.

One of the immediate consequences of closing CDEP on the far south coast was that its administering organisation, Wallaga Lake CDEP Inc., was dissolved. This is significant in itself because, as in many locations, the CDEP organisation had become much more than the provider of publicly funded services and taken on a broader role as a social and institutional actor in the region (see Rowse 2001; and Altman, this volume, for an institutional analysis of CDEP). It is also significant from a research perspective in that, unfortunately, very few written records from Wallaga Lake CDEP Inc. remain. Material for this chapter is therefore drawn from relevant secondary sources as well as a series of interviews and discussions undertaken during several visits between 2012 and 2015; these were with former CDEP participants, other Aboriginal residents in the region, and staff 
of Local Aboriginal Land Councils and mainstream employment services. While individuals are quoted here, no names or identifying characteristics have been included. This is to protect the anonymity of research participants who live in relatively small communities and where tensions surrounding the closure of CDEP are, for some, still felt deeply.

Social policy is always complex, and while many Aboriginal people on the far south coast want to see increased employment within their communities, some do now believe that CDEP was relied on too heavily, or for too long. Equally, however, they are unsatisfied with the current alternative, which sees many people unemployed longterm and finding little benefit from their interactions with mainstream employment services. This chapter suggests that rather than relying on an overly simplistic distinction between the needs of 'urban' and 'remote' Aboriginal people, policy settings for places like the NSW far south coast should be reconsidered in light of unique local challenges and opportunities. New strategies - based on genuine consultation and perhaps drawing on old ideas like a Community Employment and Enterprise Development scheme-are needed to support both increased employment and improved livelihoods for many Koori residents of the region.

\section{CDEP in urban and regional Australia}

Although CDEP was originally envisaged as a program for remote areas, from 1987 it expanded into regional and urban locations. This followed the 1985 Miller Review that highlighted what the review committee saw as successes of the program and recommended an exploration of 'its potential beyond the distinctive remote community context' (Miller 1985: 407; also see Appendix 1, this volume).

The Hawke Government's response to the Miller Review was the 1987 Aboriginal Employment Development Policy (AEDP). A key feature was the expansion of CDEP into non-remote areas with the aim of achieving employment equity between Indigenous and non-Indigenous people by the year 2000. Policymakers at that time saw participation in CDEP as a legitimate form of publicly funded employment and justified the program's expansion on several bases. First, they argued that in and around small country towns employment prospects for Aboriginal 
people were bleak because the agricultural employment base had virtually disappeared, and because common recruitment methods put Aboriginal people at a disadvantage:

most job vacancies in such areas are either filled through personal contact with the employer (noting that there are few Aboriginal employers) or by the recruitment of staff from outside the local area (Australian Government 1987a: 5).

Further, they listed a number of reasons why 'some Aboriginal people living in urban and rural areas' were 'not able to compete for jobs in the open labour market', including 'the desire to work in an Aboriginal working environment, a lack of marketable job skills and discouragement due to entrenched long-term unemployment ${ }^{\prime}$ (Australian Government 1987a: 5).

The AEDP was clearly framed around the notion that Indigenous people have a right to self-determination, and the policy approachincluding the expansion of $\mathrm{CDEP}$ - was seen as supporting that right by ensuring efforts to attain employment equity were 'consistent with Aboriginal social and cultural values' and circumstances (Australian Government 1987a: 3). This again reflected a strong sentiment in the Miller Review that Aboriginal control over delivery of CDEP was one of the program's principal strengths. The review committee reflected positively on the control that Aboriginal people were able to exercise over CDEP, with 'the role of government officers being to facilitate decisions, rather than to dictate the options available'. They cautioned against governments 'using programs as a means to interfere and coerce people into action they believe to be appropriate' (Miller 1985: 363). Implicit in the review's recommendations was the notion that self-management would be equally productive in remote and more densely settled areas.

With CDEP's expansion following the introduction of the AEDP, the program operated in many non-remote areas for close to 20 years. As in remote locations, the non-remote CDEPs had a variety of functions including income support, enterprise development, employment creation, cultural production, institutional and financial support for self-management and investment in community infrastructure and equipment (see, for example, Australian Government 1987b; Altman \& Sanders 1991; Altman \& Smith 1993; Rowse 2002: 67; Smith 1995). However, as Chapter 2 identified, characterisations of the 
scheme changed dramatically during those 20 years, from a focus on supporting these multiple aspects of Indigenous social and economic development to a principal focus on transitioning participants into non-CDEP jobs. Briefly reflecting on those changes helps put the closure of CDEP on the NSW far south coast into this much broader, and highly contentious, context.

\section{Praise for CDEP, and a growing focus on non-CDEP jobs}

Major reviews in the early 1990s were largely favourable towards CDEP, including its operation in rural and urban areas (some of these reviews are further documented in Appendix 1). The 1991 Royal Commission into Aboriginal Deaths in Custody (RCIADIC) suggested that 'despite its shortcomings and considerable room for improvement, [CDEP] is one of the most successful programs presently operated by the government' (RCIADIC 1991: 437). It noted examples of 'successful' CDEP schemes supporting enterprise development, the construction of community infrastructure and a lessening of problems like alcohol abuse, violence and criminal behaviour. The Commission's recommendations for CDEP included that the government consider further expanding it '(or some similar program) to rural towns with large Aboriginal population and limited mainstream employment opportunities for Aboriginal people' (RCIADIC 1991: 439). This led the Australian Government to substantially increase the number of CDEP participant places.

In 1992, a parliamentary review into the specific needs of urban dwelling Indigenous Australians ('Mainly Urban') found CDEP 'proving of great value in rural towns' where there was intractable and structural Aboriginal unemployment (HRSCATSIA 1992: 114). In these and other non-remote areas there was evidence that it engaged participants in a wide range of productive activities as well as providing 'valuable social effects', including improved selfesteem within Aboriginal communities, increased school attendance among children, improved relations with non-Aboriginal people in country towns and a lessening of social problems associated with unemployment (HRSCATSIA 1992: 116). Like the Royal Commission 
it recommended increasing the coverage of CDEP, here suggesting a substantial expansion particularly into urban areas (HRSCATSIA 1992: 120).

Despite these mostly favourable reviews, concerns were raised relatively early on that CDEP could function to create a 'second' labour market in CDEP jobs while potentially institutionalising exclusion from mainstream employment (see, for example, Altman \& Sanders 1991; Altman \& Smith 1993). This was seen as problematic because, it was argued, jobs in the conventional labour market could better provide opportunities for higher wages and overcoming material poverty (Smith 1993). The Royal Commission, too, suggested there should be a clearer distinction between the aims of CDEP in different locations, with CDEP able to provide ongoing income support for 'subsistence' communities but focusing on mainstream employment, or establishing profitable enterprises, in other areas:

It is especially important that means be devised to ensure that (unless the scheme is being used primarily as income support for a subsistence community) the CDEP scheme operates as a means to achieve a greater degree of self sufficiency, through the generation of employment in the public or private sector, or through the development of profitable enterprises (RCIADIC 1991: 439).

Ultimately, the Commission argued, CDEP should 'serve as a springboard to less artificial and more independent ways of improving the economic position of community members', with projects being 'a means to enhanced economic independence for Aboriginal people rather than simply becoming institutionalised as another form of welfare dependency' (RCIADIC 1991: 428). For these reasons, both the Royal Commission and 'Mainly Urban' reviews recommended sunset targets for $\mathrm{CDEP}$ - the former advocating for a sunset clause 'where enterprise development is the aim of a project' (RCIADIC 1991: 428 ) and the latter where the scheme 'is operating as a labour market program' (HRSCATSIA 1992: 120). In principle, these would have put a time limit on CDEP funding for some individuals. ${ }^{1}$

1 A one-year time limit was much later introduced for non-remote participants in July 2006 but, by the end of the 12 months, those non-remote schemes had been closed entirely in any case. 
By the late 1990s, the argument that CDEP was institutionalising exclusion from mainstream employment was becoming increasingly influential, perhaps in spite of evidence that many CDEPs were by now effectively transitioning people into non-CDEP jobs. An assessment by the Aboriginal and Torres Strait Islander Commission (ATSIC) Office of Evaluation and Audit (1997) - focused especially on the outcomes of urban CDEP programs - found that individuals who had participated in urban CDEPs had better mainstream employment outcomes than a comparison group of non-Indigenous jobseekers registered with the then Commonwealth Employment Service. This indicated 'a positive impact of the urban CDEP on employment outcomes for its participants' (ATSIC Office of Evaluation and Audit 1997: i). However, the release of the so-called 'Spicer Review' of CDEP in the same year is sometimes seen as a turning point in the prevailing political attitudes towards the scheme. Overall it was supportive of CDEP and highlighted the wide range of personal, social, cultural and economic benefits that could flow from it. Nonetheless, it placed special emphasis on the need to equip participants for non-CDEP employment, and while it found 'many examples' where CDEP had enabled participants to move into mainstream jobs, it argued that:

The overriding challenge is to ensure that, where possible, CDEP does not become a life time destination for all participants but provides a conduit to other employment options. While work that facilitates community development must remain an important part of CDEP, greater attention in the future must be given to meeting the needs of the individual participants in order that they acquire new skills to access new employment opportunities, where they exist (Spicer 1997: 4-5).

\section{A 'dead end' for employment? The curtain call for non-remote CDEPs}

The policy response following the Spicer Review included placing increasing emphasis on performance measurement of CDEPs, especially in relation to non-CDEP employment outcomes and the facilitation of skill acquisition suited to mainstream jobs (see Sanders 2001; Whitby 2001). These outcomes, after all, seemed the most easily measurable. From 2002, CDEPs in some regional and urban areas were also encouraged to become 'Indigenous Employment Centres'; these were to be focused specifically on transitioning CDEP participants 
into other jobs or employment assistance (Champion 2002). As noted in Chapter 2, this focus on mainstream employment outcomes became even more dominant after the dismantling of ATSIC in 2004, when CDEP was moved into the Department of Employment and Workplace Relations (DEWR).

The 'fit' between CDEP and the employment department may well have been uncomfortable; the former with its original list of broad, often intangible goals and the latter with a clear focus on getting more Australians into paid work. Nonetheless, Kevin Andrews, the minister then responsible for the employment portfolio, did publicly express support for CDEP even if only on the basis of job outcomes. As late as July 2006, he praised the scheme for substantially increasing the number of participants transitioned into mainstream employment, with over 3,500 people moving into non-CDEP jobs in the previous 12 months. This, he announced, represented a 135 per cent increase on the preceding year (Andrews 2006a). Again in October 2006, Andrews announced the scheme was 'performing strongly' on mainstream employment outcomes, including in urban areas, and while he was 'delighted with this result' he looked forward 'to even better results in the future' (Andrews 2006b).

Within a few weeks, however, the government's public pronouncements about CDEP had changed. Mal Brough, then Minister for Indigenous Affairs, declared that the scheme needed to be further overhauled 'so that it does not continue to be a dead end for people where there are jobs available' (Brough 2006). On 6 November 2006, Kevin Andrews released the Indigenous Potential meets Economic Opportunity Discussion Paper in which he announced the government's intention to close CDEP in urban areas and major regional centres. Replacing CDEP with the Structured Training and Employment Projects (STEP) brokerage service would increase the focus on placement directly into jobs taking advantage of the strong employment opportunities provided in these areas' (Andrews 2006c).

This approach may seem contradictory given Andrews' earlier reflections on CDEP's employment success. According to DEWR, however, by replacing CDEP with the new STEP services job outcomes 
would be further improved. ${ }^{2}$ Along with the closure of ATSIC, this new direction dovetailed neatly with the Howard Government's explicit rejection of self-determination as an appropriate policy framework for Indigenous affairs. Some government ministers argued that existing policies had encouraged separatism and entrenched the prolonged exclusion of Indigenous Australians from the market economy and 'normal' Australian life (see, for example, Brough 2006). Despite its move from ATSIC into DEWR, CDEP had remained a unique institution premised on the notion of Aboriginal and Torres Strait Islander people having distinct needs and, as such, was a clear target for 'mainstreaming' in line with the government's broader ideological approach.

In mid-2007, only three years after DEWR had taken responsibility for CDEP, around 60 urban and regional CDEPs were closed (Hunt 2008: 36). These were deemed to be in areas with strong labour markets, corresponding to unemployment rates of below 7 per cent. The closures directly affected around 6,000 people (Altman 2007: 1). Unfortunately, a government review of the impacts of closing CDEPs in urban areas in 2007 was terminated very shortly after it commenced, and no results have been publicly released (Steering Committee for the Review of Government Service Provision 2009: 4.71). Some evidence of the effects of closing non-remote CDEPs - garnered from questions put to a federal Senate committee - suggested that by March 2009, 40 per cent of former participants were receiving unemployment benefits. It was not known how many had moved into alternative employment or how many had exited the labour force. In the absence of more evidence at the national level, the remainder of this chapter focuses on local evidence from the closure of CDEP on the NSW far south coast.

2 STEP provided funding and assistance to employers to take on Indigenous staff. Assistance could include, for example, pre-employment training services, the development of Indigenous recruitment strategies, and post-placement mentoring services for Indigenous employees. It was envisaged that STEP could also provide 'community work activities', which would be similar to CDEP activities, for clients who were 'not ready for training or job placement' (DEWR 2006: 8). 


\section{CDEP on the NSW far south coast}

In this chapter the far south coast of NSW is defined as the region from Eden in the south to Wallaga Lake, around $100 \mathrm{~km}$ to the north. The region therefore includes small coastal towns such as Bermagui as well as the larger inland centre of Bega. This definition reflects the way CDEP was organised in that, until 30 June 2006, CDEP in Wallaga Lake, Bega and Eden was run by a single organisation-Wallaga Lake CDEP Inc. - which provided central administration for work crews in each of the three locations.

\section{The NSW far south coast}

The 2011 census shows the Aboriginal and Torres Strait Islander proportion of the population of the far south coast to be slightly higher than the nationwide figure at the time (around 3.3 per cent compared to 2.7 per cent). ${ }^{3}$ There are a number of locations where this figure increases substantially, including Bega (where, in 2011, 6 per cent of the population were Aboriginal or Torres Strait Islander), Eden (8 per cent) and Wallaga Lake (92 per cent). ${ }^{4}$

The very high proportion of people in Wallaga Lake who are Indigenous reflects the significant history of the area as an Aboriginal reserve. Established in 1891 by the NSW Aborigines Protection Board, the formation of the reserve at Wallaga Lake meant that Aboriginal people from coastal areas and inland through the Monaro Plain were brought together under the control of a state-appointed manager 5 (see Goulding \& Waters 2005; Midlam 2011; White 2010). Almost 100 years after the Wallaga Lake Reserve was established, the 1983 passage of the NSW Aboriginal Land Rights Act paved the way for an end to

\footnotetext{
3 Census data for the whole far south coast region are here derived by adding the population counts for the Wallaga Lake Indigenous Location and Bega Valley Local Government Area. The data refer to place of usual residence; this is likely to count fewer Indigenous people than reflected in the Estimated Resident Population (ERP), but ERP also shows a higher-than-average proportion of the far south coast population who are Indigenous.

4 Indigenous Locations (ILOCs), place of usual residence.

5 The land for the Wallaga Lake reserve was set aside by the Aborigines Protection Board in 1891; in 1909 the passing of the Aborigines Protection Act allowed the board to segregate the Aboriginal population (White 2010).
} 
the reserve system in that state: in 1984 the title deeds for the Wallaga Lake Reserve lands were transferred to the local Koori community (Midlam 2011).

Now known as the Wallaga Lake Koori Village the area is home to a fluctuating population usually between around 100 and 150 people. The village is managed by Merrimans Local Aboriginal Land Council, who act for Aboriginal people across a much larger geographic area; this includes Wallaga Lake and nearby coastal locations but also stretches over $100 \mathrm{~km}$ inland (Merrimans Local Aboriginal Land Council 2014: 8). The Koori communities in and around Bega and Eden are larger than at Wallaga Lake: in 2011 each of these two locations was home to around 230 Aboriginal people (ABS 2011). Both Bega and Eden have separate Aboriginal land councils. Along with Merrimans, the three land council regions comprise the traditional country of several Aboriginal groups; these include the Yuin in the coastal areas and the inland country of the Ngarigo-speaking people of the Monaro region. ${ }^{6}$ Historically, the Monaro and Yuin moved across the region at various times, with coastal people travelling to the alpine areas during summer, and some tribes travelling to the coast during winter (Cruse et al. 2005; Hunt 2013: 8; White 2015). Throughout the region-and as far as Sydney, the north coast of NSW and parts of Victoria - strong kinship networks between Aboriginal communities remain, and there is significant mobility between these locations.

The relatively high Aboriginal proportion of the population in the far south coast region likely reflects, in part, a more general trend along the NSW coast in which European settlement tended to alienate inland areas before coastal ones (with the former initially deemed more economically productive because of a priority on agriculture, forestry and mining). This meant that land along the coasts was 'largely seen as not useful' and 'for a long time left vacant by settlers, enabling Aboriginal people to live or camp by the sea while remaining out of sight, and working in local industries' (NSW Office of Environment and Heritage 2012: 1).

6 For more information about the Aboriginal heritage of the region there is a significant published literature. See, for example, Chittick and Fox 1997; Donaldson 2006, 2008; Egloff, Peterson and Wesson 2005; Wesson 2000; White 2015. 
For many years, Aboriginal people in this area worked seasonally as agricultural labourers, especially picking beans and peas (White 2010; see also Egloff et al. 2005; McKenna 2002). They were also heavily involved in fishing and maritime industries, both for consumption and commercial purposes, with Aboriginal involvement in commercial fishing dating back to at least the early 19th century (Egloff et al. 2005; NSW Office of Environment and Heritage 2012: 22; see also Cruse et al. 2005). By the early 20th century, many south coast Kooris were working for wages in these industries, or in commercial forestry operations (such as at saw mills) or as domestic workers (Feary \& Donaldson 2011: 9).

It is often said that industries like agriculture, fishing and forestry suited Aboriginal people on the south coast well, allowing them to maintain access to country and continue to utilise and pass on traditional knowledge, as well as providing flexibility and supporting the maintenance of social and cultural relationships (see, for example, Cruse et al. 2005; Donaldson 2006; White 2010). For example, much of the work was seasonal and allowed families to work together and travel up and down the coast where they could camp on country and meet with other families travelling the same routes. Sue Donaldson (2006: 121) has argued that, for these reasons, work like seasonal farming jobs 'remained in keeping with the traditional transient, family oriented lifestyle maintained by many Aboriginal families' and 'encouraged the maintenance of kinship links and ensured cultural links to the land were maintained'.

Aboriginal employment in agriculture, forestry and fishing declined very substantially in the late 20th century. Demand for Aboriginal labour fell as these industries themselves went into decline, coupled with increasing mechanisation (Donaldson 2006; Hunt 2013; White 2010). At the same time, increased access to town housing and social security payments may have reduced the supply of Aboriginal workers for these jobs (White 2010). The implications of these changes are ongoing: apart from employment in CDEP, Aboriginal employment on the far south coast has remained low, with consequences not only for peoples' financial position but also for opportunities to maintain social and cultural relationships and connections to some parts of their country (see Hunt 2013; NSW Office of Environment and Heritage 2012: 31). 


\section{CDEP on the NSW far south coast}

CDEP was introduced to the NSW far south coast around 1989 when the Wallaga Lake Koori Village opted into the scheme. This was only five years after the title deeds for the Wallaga Lake Reserve lands had been transferred to Aboriginal ownership and, interestingly, around the same time that CDEP arrived in the much more remote Maningrida region, as detailed in Chapter 7.

Setting up a CDEP scheme at Wallaga Lake also meant establishing an administering organisation there - this initially comprised just a CDEP manager and was first run from the manager's home. An administering organisation with an Aboriginal board was subsequently incorporated as Wallaga Lake CDEP Inc. In the context of CDEP rolling out into urban and regional areas, the Wallaga Lake scheme came relatively early, with the program opened to non-remote locations only from 1987. By that time, local industries - especially those that had a history of employing Aboriginal people - had started to decline and unemployment in the region was rising.

According to those involved at the time, when the Wallaga Lake CDEP was established it had around 30 participants, but this grew to around 50 participants within the first six months. Other communities on the far south coast had initially been sceptical about the scheme, but by the early 1990s they were also keen to come on board. By 1995 new schemes in Bega and Eden were amalgamated with Wallaga, with a work shed and work crew in all three areas. The combined total of up to around 120 people was initially administered centrally from Wallaga Lake (and later from Bega).

Those working for CDEP were employed in a range of work projects, many of which incorporated formal training and some of which brought a commercial return. The scheme was used to support several enterprises including the Umbarra Cultural Centre (just outside Wallaga Lake community), which sold locally produced arts and crafts, maintained a small museum for visitors, ran boat tours on Wallaga Lake and 4WD tours on nearby Gulaga mountain. CDEP was also used to establish a number of additional small enterprises, including commercial cardboard recycling, lawn mowing and a firewood scheme that serviced both Aboriginal and non-Indigenous residents of the south coast. The firewood enterprise, for example, meant negotiating 
a contract with Forests NSW to harvest firewood from State Forests and on-sell it to retailers. It required CDEP participants to be formally trained in first aid and licensed to use chainsaws for tree falling. As well as generating significant commercial returns, this enterprise facilitated the free delivery of firewood to elderly Aboriginal residents of the region. Firewood and lawn mowing crews operated from Bega, Eden and Wallaga Lake, with cardboard recycling run from Eden. The self-generated funds allowed industrious workers to earn top-up over and above their standard CDEP wages, as well as giving some workers the opportunity for promotion to supervisor.

Other activities provided essential services for the Wallaga Lake Koori Village - such as rubbish collection, burial services and yard maintenance. Still others at Wallaga Lake were centred on exploring the commercial potential of possible enterprises in oyster farming and furniture making, as well as projects geared towards self-sufficiency (with CDEP running a substantial market garden including two paddocks and a purpose-built dam).

In Bega, Eden and Wallaga Lake, activities also included opportunities for on-the-job training (such as through housing construction projects), subsidised work placements and the completion of formal qualifications and licensing requirements - the latter usually for driving vehicles or operating machinery. Subsidised work placements were made in Local Aboriginal Land Councils and Shire councils (e.g. providing administrative support) and as Aboriginal Education Officers in public schools. From 1999 women began participating in CDEP activities, sometimes in tailored programs (such as sewing and catering or subsidised work placements like office administration) and sometimes in the male-dominated activities like firewood harvesting and building construction. Several participants moved off CDEP into other paid jobs (including with Shire councils and Forests NSW); this will be returned to later in this chapter.

In creating economic development opportunities and supporting a range of community services, the scheme also invested in substantial capital and equipment that could be used for community benefit. This included tractors, trucks, a boat, chainsaws and log splitters, as well as land that was intended for development to bring a commercial return. 
The way CDEP was managed sought to match local realities on the far south coast, reflecting one of the original aims of CDEP as supporting self-management. For example, participants were rostered on for two days per week but flexibility allowed them to split those hours over four days, swap to a different two days, or add an extra two days for top-up. Work crews were allocated to each of the various CDEP activities, with participants rotating through the different jobs over time to multiskill. Where one work crew needed assistance for a particularly large job, another could travel from a satellite location to provide support.

This flexibility was an important element of the scheme, differentiating it from more 'mainstream' employment in several ways. For example, it allowed a changing balance of work and other commitments as peoples' needs and family responsibilities fluctuated. This often sat more comfortably with local availability for paid work than the requirements of a full-time job, and formed somewhat of a continuum with the way Aboriginal people had engaged seasonally and flexibly in fishing, agricultural labour and cultural activities in earlier generations. Some local people point to the opportunity for communal types of work and training as particularly beneficial for Aboriginal jobseekers. According to one Aboriginal resident of the region:

The grandparents could all work together as a community, so they could still do cultural stuff together. But [before CDEP] the next generation couldn't do that - they had to find individual work. Some did, but not the majority.

(local Aboriginal resident)

Significantly, CDEP was also an Aboriginal workplace where supervisors were better able to understand the needs of their workers than many non-Aboriginal employers. In addition, it allowed participants to earn an income without exposing themselves to what has long been perceived as widespread racism towards Aboriginal people in the region. Training was often conducted 'on the job' rather than in classrooms, with many participants having had negative experiences of classroom learning in the past. A number of people on the far south coast remember CDEP as providing an opportunity to work together in an environment of understanding and peer support: 
With CDEP the manager was always well known in the community. So they knew peoples' issues and could work with them.

(former CDEP participant)

People got a lot of training out of it [CDEP]. Now, even if a course is offered, people have to go on their own. It used to be a big group of them would go, so they could help each other if they couldn't read or write.

(local Aboriginal resident)

In these ways CDEP allowed what has previously been called an 'Aboriginalisation' of work (Altman \& Smith 1993: 7; Smith 1995: 6). On some accounts it was the 'most radical aspect' of the scheme (Altman \& Smith 1993: 7), but on the far south coast the nature of the CDEP workplace as a 'self-determined space' became an attraction in itself for participants to turn up. By and large, it meant that CDEP was much better placed than many mainstream employers to engage Aboriginal people in work and training, given the particular economic and cultural characteristics of the region.

Many people involved in CDEP recall that as well as delivering the formal elements of the program in training and employment, the far south coast scheme had significant benefits for individual and community well-being. For example, it is a common recollection that CDEP helped to bring the Koori communities of the south coast together in a way that had not happened for some time before, easing tensions in relationships between families and providing opportunities for shared goals and activities. Many people also argue that encouragement to engage in CDEP, within a supportive and productive environment, created a sense of pride and enthusiasm among participants and helped some people 'get off the grog', stop using drugs and-for those previously engaged with the criminal justice system-avoid a return to jail. Because it could offer guaranteed work, CDEP could also support supervised prisoner release.

It was deadly with CDEP, beautiful. Before that people were getting the dole, drinking and partying. But then [with CDEP] people started getting paid, working, and that was good. It was good times for the kids ... there was jobs everywhere.

(former CDEP participant) 
Such recollections of CDEP among former participants are remarkably similar to the views documented in several reviews of the scheme discussed earlier in this chapter, as well as in previous case study research. Diane Smith's research in urban Redfern in the mid-1990s found that CDEP was not only an 'economic endeavour' but also 'part of a social process which is pre-eminently Aboriginal' and an important part of the Aboriginal community's social fabric (Smith 1995: 6). The ATSIC Office of Evaluation and Audit review that focused especially on urban CDEPs found that the program brought 'a strong sense of pride and hope' to the community, partly because services were delivered 'within a self-governing framework' (ATSIC Office of Evaluation and Audit 1997: ii). It also found that 'tangible and objective benefits' of the scheme included 'significantly higher incomes, lower alcohol consumption, lower number of police arrests, and higher cultural identification' among CDEP participants as compared to unemployed Indigenous people, and argued this had important implications for addressing the increasing incarceration rates and 'cultural alienation' of Indigenous people in urban Australia (ATSIC Office of Evaluation and Audit 1997: ii).

\section{Winding up Wallaga Lake CDEP Inc.}

After more than 15 years of CDEP on the far south coast, the mid-2000s saw it draw to a close. On 1 July 2006, administration was transferred from Wallaga Lake CDEP Inc. - a local Aboriginal organisation with an Aboriginal board - to Campbell Page, which was a not-for-profit company tasked with delivering the Australian Government's Job Network and other employment services. ${ }^{7}$

Although it was generating a significant amount of its own income, Wallaga Lake CDEP Inc. was informed by DEWR that it would not be able to trade beyond 30 June 2006, and that it would be wound up as a corporation. A liquidator was appointed to sell off the corporation's assets and finalise its liabilities. The announced closure of Wallaga Lake CDEP Inc. - well before DEWR announced the intended closure

7 Trading then as Oasis Pre-Employment Network (OPEN) Inc. 
of other non-remote CDEPs - took CDEP supervisors and participants on the far south coast by surprise. They were given only 15 days' notice of the change.

Campbell Page continued running the CDEP scheme until late 2007, when it became one of the 60 or so programs in non-remote locations that were closed-apparently because they were in regions with strong local labour markets. ${ }^{8}$ In the year leading up to the closure, the directive from DEWR was that Campbell Page should prioritise moving CDEP participants into non-CDEP jobs wherever possible, and get CDEP activities that were generating a commercial return to a point where they could be sustainable without CDEP wages. Under Campbell Page all CDEP participants were placed with host employers, including with Local Aboriginal Land Councils. In mid-2007, a performance review criticised the lack of conversion from hosted placements to non-CDEP jobs, and advised the scheme would be closed. Although there is still confusion among local residents about why CDEP was transferred to Campbell Page and then terminated, some believe that giving it to Campbell Page was principally a way for the government to 'contract out' the scheme's closure and the inevitable contestation it generated. The next sections explore what happened when CDEP closed on the far south coast of NSW, and the ongoing implications for Aboriginal people in the region.

\section{The employment implications of closing CDEP on the far south coast}

When Wallaga Lake CDEP Inc. closed it had around 80 participants; around 40 to 50 of these were transferred to Campbell Page in July 2006. ${ }^{9}$ Although this figure is not directly comparable to the census data collected in August 2006, it does indicate that a significant proportion of the paid employment of Aboriginal people in the region was in CDEP. That is, the census recorded 77 Aboriginal people

\footnotetext{
8 Few records from this time have survived and recollections about the exact date CDEP closed diverge. There is some evidence though, in the form of employment separation certificates, that CDEP employment was terminated for all participants by January 2008.

9 The figure of 80 participants is based on the recollections of the then manager of Wallaga Lake CDEP Inc., Richard Barcham. Unfortunately, administrative records from this time have not survived. Some participants exited voluntarily after the scheme changed hands, and a significant number of listed participants never turned up to work for Campbell Page. The government's administrative data for August 2006 record 41 participants registered with Campbell Page (see Chapter 3), but those involved in the scheme at the time recall that there were closer to 50.
} 
resident in Bega, Eden or Wallaga Lake who were employed.$^{10}$ Hence it is reasonable to assume that a very large proportion of paid Koori workers at that time were employed in the CDEP scheme.

The closure of Wallaga Lake CDEP Inc. was experienced by many local people as sudden and unexpected, even if it had been decided in government circles for some time. And although DEWR asked Campbell Page to subsequently move as many participants as possible into non-CDEP jobs, no participants had found alternative work during the period of Campbell Page's management. This meant that when the Campbell Page scheme closed in late 2007 the immediate impact on employment was profound: almost all of the remaining 40 to 50 CDEP workers found themselves unemployed. The few exceptions to this included three men based in Eden who were able to retain a truck to keep the cardboard recycling enterprise going, and a skeleton staff of three people at Umbarra who kept the centre open for around 18 months without CDEP wages until available non-CDEP funds were exhausted. The cardboard recycling operation continued until around 2012, but was never able to employ more than three people in the absence of CDEP wages; under CDEP it had employed eight. Other programs, like land management crews that were subsidised via CDEP wages, became defunct (see Hunt 2013: 20).

The government's approach in closing CDEP on the far south coast seemed to be based on several assumptions. First, that transferring delivery of CDEP to Campbell Page would assist in transitioning participants into non-CDEP employment (in effect suggesting that the management of Wallaga Lake CDEP Inc. were responsible for low mainstream employment outcomes). With this first apparent assumption quickly proving false, the second was that employment outcomes would improve in the absence of the CDEP scheme. An immediate increase in unemployment was to be expected when the Campbell Page CDEP closed, but the policy intent was that mainstream job services would subsequently move those affected into other jobs.

In the absence of appropriate data tracking the outcomes for individuals, the census is the best statistical indicator of how Aboriginal employment rates in the region changed after CDEP's

10 Data from Community Profiles for Bega, Eden and Wallaga Lake Indigenous Locations, usual place of residence. It should be noted that, unlike in remote areas, the census in non-remote locations did not record CDEP employment separately. 
closure. It should be noted, though, that the use of census data for this purpose should be treated with caution. There are introduced random errors to ensure confidentiality that can have a significant impact when the census count is small. ${ }^{11}$ Nonetheless, the census does give an indication of broad trends in Aboriginal employment in the areas likely to have been most affected by the change.

Comparing census data for 2006 and 2011 in Bega, Eden and Wallaga Lake suggests there was an increase in the unemployment rate for Aboriginal people in the region (with data from the 'Community Profiles' publications showing an increase from 21 per cent to 36 per cent over the period). Breaking it down further to each of these three locations, Table 4.1 suggests that outcomes may have deteriorated least in Bega, and probably most in Wallaga Lake.

Table 4.1 Labour force characteristics for Bega, Eden and Wallaga Lake Indigenous Locations, Indigenous people aged 15-64 years, 2006 and 2011

\begin{tabular}{|l|c|c|c|c|c|c|}
\hline \multirow{2}{*}{} & \multicolumn{2}{|c|}{$\begin{array}{c}\text { Unemployment } \\
\text { rate (\%) }\end{array}$} & \multicolumn{2}{c|}{$\begin{array}{c}\text { Labour force } \\
\text { participation rate (\%) }\end{array}$} & \multicolumn{2}{c|}{$\begin{array}{c}\text { Employment/ } \\
\text { population ratio (\%) }\end{array}$} \\
\cline { 2 - 7 } & 2006 & 2011 & 2006 & 2011 & 2006 & 2011 \\
\hline Bega & 19 & 24 & 44 & 41 & 35 & 31 \\
\hline Eden & 11 & 41 & 41 & 41 & 37 & 24 \\
\hline Wallaga Lake & 35 & 60 & 54 & 25 & 35 & 10 \\
\hline
\end{tabular}

Note: Data presented here are not adjusted for geographic correspondences. ${ }^{12}$

Source: ABS Census of Population and Housing, Community Profiles, place of usual residence.

11 For example, using the same census data sourced from two different ABS productsTablebuilder and Community Profiles - varies the apparent 2006 unemployment rate for Eden ILOC by 12 percentage points, from 11 per cent (Community Profiles) to 23 per cent (Tablebuilder). This was the largest difference observed on any of the measures in Table 4.1, and is very likely due to the introduction of random errors. This means the data should be treated with caution and is indicative of broad trends rather than absolute measures.

12 Adjusting for correspondences is usually understood to improve the accuracy of intercensal data comparisons by accounting for changes in the geographic boundaries of statistical regions. The only significant difference this makes to data in Table 4.1 is for Wallaga Lake. The area included in the Wallaga Lake ILOC in 2006 was significantly smaller than the area included in the Wallaga Lake ILOC in 2011 (i.e. 14 per cent of what was the 'Eurobodalla remainder' ILOC in 2006 was added to the 'Wallaga Lake' ILOC in 2011; this was the area at the southern boundary of the Eurobodalla Remainder ILOC immediately adjoining Wallaga Lake). However, the 2006 Eurobodalla Remainder ILOC was a very large area extending as far north as Batemans Bay; the demographic profile of the Aboriginal residents in almost all of this region would bear little relevance to the closure of CDEP in Wallaga Lake. As such, including 14 per cent of the whole Eurobodalla ILOC in the 2006 Wallaga Lake ILOC is not likely to provide a clearer indication of the outcomes of Wallaga Lake CDEP's closure. 
Of course, it is not possible to conclude that changes in labour force status are entirely due to the closure of CDEP. Other factors in the region include the continued decline of industries such as forestry and fishing that had been employers of Aboriginal people (most jobs in the region are now in service industries, especially health care and social assistance, retail and tourism). It is pertinent to note that non-Indigenous unemployment is also high, though according to the census the overall unemployment rate in the region declined slightly over the period from 7 per cent in 2006 to 6 per cent in 2011 (ABS 2006, 2011). ${ }^{13}$

Discussions with local residents suggest that most people who had been employed in CDEP on the far south coast have not since found stable employment. This is most obvious in Wallaga Lake, where the 2011 census shows only 10 per cent of Indigenous people aged between 15 and 64 years with paid jobs, and over two-thirds of people in this age group outside the labour force. This compares to the average of around one-third of the working-age population who had been employed in Wallaga Lake through CDEP at any one time.

Unemployment for younger Indigenous people on the far south coast remains especially high, at 52 per cent of 15- to 24-year-olds at the 2011 census, compared to 11 per cent for non-Indigenous people in the same age group (ABS 2011). ${ }^{14}$ However, there are some recent employment programs that have been notable for employing young Aboriginal people, including 12 people trained, and six employed, at Woolworths, and 20 people accepted for 12-month construction-based traineeships with Brookfield Multiplex. ${ }^{15}$ Increasing rates of high school completion bode well for further improvements in Aboriginal employment over time, as do additional planned initiatives such as Aboriginal owned and operated tourism services associated with the development of the Bundian Way near Eden (see Hunt 2013: 14).

\footnotetext{
13 These figures are for the Bega Valley LGA. Wallaga Lake ILOC is excluded due to data limitations, but given its small size this should not significantly affect the results. Correspondences are not necessary for LGAs unless local government boundaries change.

14 The geographic areas considered here are slightly different. The figures for Indigenous young people are derived from the Bega Valley LGA plus the Wallaga Lake ILOC, whereas the figures for non-Indigenous young people are derived from only the Bega Valley LGA. However, given the small size and demographic makeup of Wallaga Lake ILOC (92 per cent Indigenous), it can be assumed the two data sets are comparable.

15 Some of the participants in the traineeship program are from further afield, including Cooma and Batemans Bay.
} 
Nonetheless, substantial challenges in improving Aboriginal employment outcomes on the far south coast remain. None of these challenges are easily resolved, but their presence well beyond the closure of CDEP shows that limited mainstream employment outcomes under the scheme cannot sensibly be attributed exclusively to its failings. Perhaps most fundamentally, major structural barriers have continued to frustrate employment outcomes, including the very seasonal labour market and the high unemployment rate that creates strong competition for limited local jobs.

Many in the Koori community point to continued discrimination from local employers as another significant problem. Although some believe this is slowly changing, it is often seen as an enduring barrier. Several participants in this study raised it as a concern.

The majority of people who were on CDEP haven't got jobs. The main reason is that there are no jobs. The second reason is that if there are two people going for a job, and one is white and one is black, the white one gets the job.

(former CDEP participant)

Business owners make decisions based on stereotypes, and some family names have reputations, so those people find it hard. The business owner might have had one bad experience but then rely on stereotypes. (local Aboriginal resident)

The older generations did bean picking. There was less racism then, good relationships with farmers ... There were restrictions thenthey had to sit separately in the picture theatre, couldn't enter pubs, the kids couldn't go to the same school. So there were rules but at least they were known, overt. Now, the racism's covert ... it's much harder to deal with.

(former CDEP participant)

This effect of discrimination on employment is summed up simply by one former CDEP participant:

Being black has been a barrier to getting a job.

This view is strongly supported by some local job service providers. One provider, for example, has gone to the length of testing employer responses by asking an Aboriginal and non-Aboriginal person to approach the same employer on the same day and ask if they had 
any job vacancies. While the Aboriginal person was told there were no vacancies, the non-Aboriginal person was told there were three. According to a senior staff member at that job service provider:

Racism's a fact. If we're going to be successful in placing people into employment, we need to acknowledge it.

Where job vacancies exist, access can also be limited for Aboriginal people in other ways. It is relatively common, for example, not to have a driver's licence or access to a reliable car. This is a particular problem for people at Wallaga Lake because the community is geographically separate from surrounding population centres and-since the CDEP bus stopped running - there is no public transport to local towns for job interviews or indeed for regular attendance at work.

There's not much public transport to get to a job. You've got to have a car or you're stuffed.

(local Aboriginal resident)

Research reported by the Australian Government's Department of Employment also suggests that a relatively high proportion of vacancies on the south coast are filled via informal methods - that is, they are filled through informal networks or direct approaches from jobseekers rather than public advertising to solicit applications (Neville 2014). ${ }^{16}$ Interestingly, this is the same concern about recruitment methods in regional areas that the Hawke Government noted in 1987 in its AEDP. It is still the case that disadvantaged jobseekers are less likely to have the appropriate networks to be aware of these vacancies, and less likely to make successful direct approaches to employers where there is real or perceived discrimination.

Apart from the limited demand for labour and access to available positions, some people in far south coast Aboriginal communities can face additional challenges in securing paid work. While these factors are by no means universal, they can include limited experience of the requirements of formal employment, a discomfort in working in

16 Neville defines the far south coast more broadly to include the Shoalhaven, Eurobodalla and Bega Valley Shires. Data on recruitment methods are for the Illawarra Priority Employment Area for February 2014. 
predominantly non-Aboriginal workplaces, a prioritising of family obligations and caring responsibilities and the implications of physical and mental health problems including substance abuse.

With such complex and multiple barriers to paid work being relatively common, an important question is whether CDEP helped or hindered mainstream employment participation. As noted at the outset of this chapter, over time notions of the 'success' or otherwise of the program were eventually reduced to this singular issue. On this subject there are differences of opinion among local Aboriginal people. Some argue that while CDEP was helpful to a point - particularly in providing training and work experience - it had become too much of a destination and did not do enough to try to move people into other jobs.

The original aim of CDEP was great - to get them trained in CDEP and do small business (that was also about training), and we could have funded the best ones as permanent and used it to train others to move on to other jobs. But it became too much of a destination. We need to be self-sufficient and not rely on government funding.

(local Aboriginal resident)

Others point out that CDEP helped people prepare for employment by getting necessary licences, and emphasise that some participants did move into mainstream jobs. Among people interviewed for this project, it was commonly argued that the participants who transitioned into alternative employment were the individuals with the right aptitude for non-CDEP work. The rest tend to be seen within two broad groups: those not suited to mainstream jobs because of major and enduring barriers to regular employment, or those who were best able to help their peers by remaining on CDEP as supervisors and role models for other participants.

People got licences. Forklift, chainsaw, tree fallers, drivers' licences, plus upgrading them to light rigid and heavy rigid. That could help people get other jobs.

(former CDEP participant)

CDEP prepared the ones who were going to make it in other jobs well. Then there are the ones who were never going to get other jobs regardless. And you can see that many of them are still unemployed.

(former CDEP supervisor) 
On CDEP the ones that were able to would move into other work. But the ones not able to - there was nothing else for them. The best place for them was CDEP. Now they're just Stream 4 clients sitting at home doing drugs. ${ }^{17}$

(former CDEP participant)

Some of the older ones stayed on CDEP because they had the experience, they could show the younger ones what to do. The aim was to help young ones build respect and move onto other things. Respect their elders, watch what we do, get licences.

(former CDEP participant)

Making sense of divergent views about CDEP's effectiveness in assisting people into mainstream jobs can be difficult. However, some of the above quotes raise what is perhaps the most pertinent question in this debate: has the closure of CDEP improved the employment prospects of participants who had been in CDEP long-term (or other jobseekers with similar circumstances)? Most Aboriginal people consulted on the far south coast argue that such people are worse off now. For example, several believe that CDEP was more effective at engaging people in productive activity than the current system, which relies on Centrelink payments and job search assistance from mainstream employment services. It is commonly held that most people were eager to do their CDEP work, that 'no work no pay' was usually enforced, and that participants were able to model the benefits of active paid work to their children.

With CDEP we could work four days. And if we didn't turn up we got no money.

(former CDEP participant)

Wallaga Lake participants had to do their minimum hours. If they didn't turn up they got docked. It was unheard of in other places prior to those days, in the mid-'90s. We always stood by that and the participants accepted it. Because we said to them if you go out in the real world this is what will happen.

(former CDEP supervisor)

17 Under the mainstream employment service known as 'Job Services Australia', Stream 4 clients were those who had been assessed as being the most difficult to place into paid work. 


\section{BETTER THAN WELFARE?}

People saw CDEP as a job and wanted to go ... It showed the kids there were opportunities.

(former CDEP participant)

Those two days [when they were rostered on], people were on the side of the street waiting for the bus to pick them up. And they were keen for extra days when they could get it.

(former CDEP participant)

People were really keen to be involved in CDEP, it was amazing.

(former CDEP participant)

In contrast, there is a widespread concern that appointments with employment services (until 1 July 2015 called JSAs, or 'Job Services Australia') bring little benefit and that, post-CDEP, an increased proportion of people are now disengaged from productive activity or paid work altogether.

You have to go in for your appointment [with the JSA] or you get docked, but they do nothing for you ... CDEP got people off their butts and working better than the JSA does.

(former CDEP participant)

Critics said people were 'parked' on CDEP. But now they're parked nowhere.

(local Aboriginal resident)

Many people consulted for this chapter argue that one of the reasons job outcomes have remained so challenging post-CDEP is that the scheme's closure exacerbated a suite of other problems that have made increasing employment participation much harder. Some of theseincluding reduced morale, increased lateral violence and a loss of local services - are discussed in the next section. To the extent that any deterioration on these measures has reduced peoples' capacity for mainstream work, the Australian Government's determination to separate the 'employment' goals of CDEP from its other community development functions was misguided. 


\section{The broader implications of closing CDEP in the region}

Some of the most common concerns people have about the closure of CDEP on the far south coast are the broader effects on individual and community well-being. It is widely agreed that closing CDEP had a profound effect on the prevailing mood - while many people saw CDEP as a job and were usually keen to participate, they were enormously disheartened by the decision to close CDEP with no consultation and little explanation. Faced first with the forced removal of the program from community control and then the loss of employment, closure of enterprises, and pressure to return assets that were seen as belonging to the community, people felt both angry and disempowered.

We got a call from DEWR Narooma ... He said let's meet tomorrow at Wallaga Lake. We walked into the hall with all these suits - they said 'We're closing CDEP as of now' — like within a week or two ... They had the JN [Job Network] and RTOs [Registered Training Organisations] there signing everybody up.

People were dumbfounded. A few screamed out, 'What are we going to do?!' ... I was bitter.

(former CDEP participant)

On CDEP people had a purpose to get up and come into work. And they were looked up to in the community.

(former CDEP participant)

When people lost CDEP, they lost a lot of morale ... All across the state people have lost morale.

(local Aboriginal resident)

Many people perceive that relationships have also deteriorated, both within Koori communities and between Aboriginal people and others on the far south coast. CDEP provided a forum for different familiesand communities - to work together, as well as physical spaces for people to meet and talk in CDEP offices and sheds. There were clear work rules that any conflicts between individuals or families should stay outside work. 


\section{BETTER THAN WELFARE?}

We had to work together, so it kept the community together. We had to get to know each other. Now we don't see people from the other communities.

(former CDEP participant)

Enterprises like lawn mowing and firewood delivery, as well as subsidised work placements with external employers, also provided opportunities for Aboriginal and non-Aboriginal people to interact in positive ways, which went some way towards challenging negative stereotypes.

It is a common perception that in the absence of CDEP - and with nothing to replace its role in mediating relationships - lateral violence among Aboriginal people on the far south coast has substantially increased. Lateral violence is sometimes referred to as internalised colonialism' and can include:

[T] he organised, harmful behaviours that we do to each other collectively as part of an oppressed group: within our families; within our organisations and; within our communities. When we are consistently oppressed we live with great fear and great anger and we often turn on those who are closest to us (Frankland \& Lewis, in Aboriginal and Torres Strait Islander Social Justice Commissioner 2011: 52).

As well as physical violence, lateral violence can involve bullying, shaming, family feuding and social exclusion (Aboriginal and Torres Strait Islander Social Justice Commissioner 2011: 54). While disputes between Aboriginal families and individuals did exist under CDEP, including disputes about whether particular families were benefiting more from the scheme, it is a common concern on the far south coast that all of these forms of lateral violence have increased since CDEP closed.

The government stuffed everything up, divided us all. We were going to work, going shopping, it was going good. Now a big piece of the pie is missing.

(former CDEP participant)

We had riots here in 2011 [post-CDEP], partly because CDEP was the only thing that brought people together.

(former CDEP participant) 
Associated with reduced morale and increased lateral violence, many people suggest that after the closure of CDEP problems of substance abuse have also been exacerbated. Under CDEP there were strict work rules about not being under the influence of alcohol or other drugs on the job, which may have put a 'brake' on substance abuse. Now, it is a common perception among those consulted on the south coast that there has been an increase in reliance on drugs and alcohol. Some people also identify this as having increased the barriers to paid work:

CDEP was creating jobs for the young ones - it was getting them off the grog.

(former CDEP participant)

People [who had been on CDEP] just went back to the dole, drink, drugs.

(former CDEP participant)

The young ones are getting into drugs and alcohol more now, where CDEP might have stopped it.

(former CDEP participant)

When CDEP closed people were angry and upset. The crime rate went up, alcohol. People had looked forward to work on CDEP, but then everyone went on Centrelink ... Now a lot of people don't want to work, there's too much grog and drugs.

(former CDEP participant)

In addition to these personal and social implications, local people also point to the very significant effects of CDEP's closure on organisational capacity and service delivery. As already noted, when CDEP was transferred to Campbell Page, Wallaga Lake CDEP Inc. and its Aboriginal board were dissolved. Further, because the Local Aboriginal Land Councils in the region had all relied on CDEP labour to fulfil some of their functions, their capacity was substantially reduced. By hosting CDEP participants they had been able to access much-needed administrative support, employ cleaners for their offices and facilities, and provide local services like maintaining common areas and community assets. When CDEP closed there was no immediate alternative funding stream to continue many of these services, and some of the services have never been re-funded or revived. For example, although Merrimans land council has been able to employ a part-time administrative assistant, both Bega and Eden land councils 
have often had to fulfil their very wide-ranging functions as peak Aboriginal organisations with only one paid member of staff..$^{18}$ Eden land council has had long periods without a cleaner, and Merrimans has had very little funding to maintain common areas in Wallaga Lake Koori Village. As one staff member of an Aboriginal organisation describes:

CDEP was good because we could bring people in for admin support and training for two days a week. We'd love to have it back. It also supported other Aboriginal organisations the same way.

The impacts of the closure of CDEP also extend to the loss of some other essential services. When CDEP stopped so too did the only regular bus service and individual rubbish collection for Wallaga Lake Koori Village. The CDEP bus that had taken residents shopping or to appointments could no longer operate. And for six months residents of the village were without individual rubbish collection as the local shire council would not send its trucks onto the privately owned roads. This meant that rubbish continued to pile up at the 35 houses until a resident with a vehicle could drive it the one kilometre out to the public road.

At the same time, not only did almost all of the CDEP enterprises close, but most of the CDEP equipment - including trucks and machinerybecame unavailable for community purposes. Although many assets had been purchased, in part, with funds self-generated through the work of employees in CDEP enterprises, DEWR deemed that these were CDEP assets and should therefore be transferred to Campbell Page to continue running CDEP.

There are different recollections among those consulted for this study about which assets were transferred to Campbell Page. However, there is general agreement that the only large assets retained by Aboriginal organisations were the boat used for tours at Umbarra Cultural Centre and the truck used for the recycling enterprise at Eden. Proceeds from the sale of other large assets - including a land holding in Bega that was intended for development for community benefit - were withheld by the Australian Government. A portion of these proceeds paid off a

18 Eden Local Aboriginal Land Council has been able to employ project officers with special funding for the Bundian Way project, but they have no responsibility for assisting with normal land council functions. 
tax debt Wallaga Lake CDEP Inc. had incurred, but there was a welldeveloped plan to pay off this debt through self-generated funds had the scheme not closed, and it remains unclear how much, if any, additional revenue the government retained after the sale.

We had the car yard in Bega-half from self-generated funds, we'd bought the block. But they came and took the lot. We had approval for a subdivision and a buyer to recapitalise. But DEWR wouldn't let it happen.

(former CDEP supervisor)

Some CDEP participants recall that DEWR requested all other items be returned-including lawn mowers, whipper snippers, chainsaws, metal-working equipment and even the diesel pump in the dam at Wallaga Lake that had helped irrigate the market garden. Many remain deeply disappointed that the vehicles, equipment and land they helped purchase through their own labour in CDEP enterprises were effectively lost to the community. Some describe the ongoing bitterness they feel when they see trucks that they worked hard to buy through CDEP now being driven by non-Indigenous people who purchased them at government auction. It is a common concern that many of the productive activities undertaken through CDEP cannot be done without new funding for equipment, even though there are willing workers.

All the equipment - we needed it badly to keep businesses going. We had several trucks ... Some were from self-generated funds, but we couldn't touch them. No rights whatsoever.

(former CDEP participant)

With CDEP we used to do funerals ... but now we need a backhoe to dig graves. At the moment a contractor does it but it's expensive and unreliable.

(former CDEP participant)

The yard maintenance, lawn mowing, wood sales all stopped ... We wanted to keep the tractor, plough and slasher for the veggie garden, and for the old people, doing their yards and getting wood. But now these services are all gone. The cemetery's not mown. They should have left the equipment.

(former CDEP participant) 
Many of the issues canvassed here-including increased substance abuse, lateral violence and disengagement from productive activityshould properly be of concern in their own right. However, they also suggest that in helping to address these enormously complex issues, CDEP was likely assisting people to become more employable, even if the outcomes of this were slow and hard to measure and resulted in non-CDEP jobs for only a few.

\section{Implications}

This chapter shows that CDEP on the far south coast of NSW was never 'just a jobs program'. Defining it in this way, the government of the day overlooked the broader social, community and enterprise development functions of the scheme, as well as the intrinsic connection between improved social outcomes and individual capacities to participate in mainstream work.

The evidence presented here focuses on just one region where CDEP was closed. It is certainly possible there are other locations where the scheme's closure was experienced as an improvement. This is most likely in areas where CDEP had not been working well. Nonetheless, the far south coast of NSW is not the only regional location where the demise of CDEP has been implicated in deteriorating outcomes. Media reporting on the closure of CDEP in Toomelah in western NSW, for example, suggests that the aims of increased employment have not been met and the broad social and economic benefits of the scheme have been undermined. This appears to have had devastating results for local residents, who were not only faced with the loss of jobs but also the loss of essential services and increased material poverty, violence and crime (see Graham 2012).

There are other notable comparisons between Toomelah and the experience on the NSW far south coast. These include the problem of racism among potential employers in the surrounding region that limited job opportunities once CDEP closed, as well as the increased pressure on an overstretched local Aboriginal land council in the absence of the services CDEP had provided. Two cases can never be considered representative of the whole, but it is certainly reasonable 
to assume that along with Toomelah and the far south coast of NSW, there would be other regional and urban areas that have faced similar challenges with the loss of CDEP.

None of this should come as a surprise. Indeed, there was substantial opposition in the lead-up to the closure of urban and regional CDEPs from a wide range of stakeholders. Community organisations expressed concern that it would lead to 'disappointment, anger, lowering of morale, and disempowerment' (Redfern Residents for Reconciliation 2006; see also Graham 2012). Demonstrating the fickle nature of politics in Indigenous affairs, members of the Australian Labor Party (who would later oversee the closure of CDEP in remote areas) argued strongly against the change. Closing CDEP in urban and regional locations was, they maintained, ignoring 'the essential job it does for community development' (Snowdon 2006), and overlooking the way that CDEP's broader functions could target the causes of lower economic participation among Indigenous Australians (Evans 2006). For those reasons, Warren Snowdon (then Shadow Parliamentary Secretary for Indigenous Affairs) argued that treating CDEP as simply an employment program was a mistake (Snowdon 2006).

Nonetheless, the many challenges faced by CDEPs in transitioning participants into mainstream jobs apparently sealed their fate. How effective the far south coast scheme was on this measure is difficult to discern. Certainly, it directly helped some individuals find non-CDEP work. By offering training, work experience and support to get relevant licences - as well as more intangible functions like peer support, role modelling, and encouragement to stay 'off the grog' - it also ensured others were as well-equipped as possible to find alternative jobs. That said, many participants saw themselves as productively employed in CDEP and were content to stay in the scheme, and some faced such substantial barriers to employment that other options were not available. For most former participants, closing CDEP in favour of mainstream employment services has not led to sustainable non-CDEP jobs. They remain unemployed or outside the labour force, and on the far south coast it is widely believed that the welfare and livelihoods of those individuals - as well as their communities - have substantially deteriorated. 
This suggests that the mainstream services currently on offer are inadequate for the needs of many Indigenous people, even in this densely settled area of the NSW coast. In the strong push for 'mainstreaming' of services, important elements of what CDEP was originally designed for-particularly its community and enterprise development functions - have been lost. If there are lessons here, they must surely include caution in choosing ideology over evidence, and a warning against seeking simple solutions to complex and multifaceted problems. But they also suggest that to improve the livelihoods of Aboriginal people in this region something beyond the current 'mainstream' is required.

This may necessitate a rejection of the overly simplistic division of Indigenous policy into 'urban/regional' and 'remote'. Policy decisions have too often been made on the assumption that there is a clear distinction between the needs and opportunities of Indigenous people in urban and regional areas from those in more remote locations. However, as Diane Smith argued more than 20 years ago, urban Aboriginal populations are diverse, and some may share characteristics 'more akin to remote communities' (Smith 1995: 13-14). This can be maintained for the far south coast of NSW where there is significant labour market segregation and a range of enduring demand- and supply-side barriers to mainstream employment. Indeed, many of the challenges facing urban and regional Aboriginal populations that were identified in reviews in the 1980s-including barriers to equal competition in the open labour market, the desire to work in a more 'Aboriginalised' work environment, and discouragement due to long-term unemployment - can equally be said for parts of the NSW far south coast in 2016. In the 1980s, recognition of these challenges encouraged the expansion of CDEP into urban areas; today, the persistence of these issues suggests that a specialised service approach is still required.

The need for tailored services is now compounded by discouragement from the last decade of 'top down' policymaking that has actively undermined local community institutions and initiatives. A scheme that many local people perceived as working well has been closed, and what were seen as community resources and equipment have been alienated. Among the people consulted for this study there is a pervasive belief that this is to the ongoing detriment of the Koori community. It is reasonable to assume that the reduced morale and 
enduring anger and frustration commonly identified have had flow-on effects for peoples' motivation to engage with mainstream institutions. Addressing these concerns will require a recommitment of governments to genuinely consult with Koori residents about their needs and priorities, and a renewed targeting of resources to support ground-up and community-based initiatives.

Many local people have a vision for their communities, and while they are actively seeking to improve outcomes, they are limited by a lack of support and resources. At Wallaga Lake, for example, a men's group has recently been established to voluntarily fulfil some of the functions of the old CDEP. With no regular source of funding, they successfully secured finances from the visiting drug and alcohol service to resurrect the badly dilapidated CDEP shed. Before work commences, however, they need to find funding for basic work gear like gloves and boots. According to one participant:

The men's group's gonna be like CDEP but without funding and equipment.

(former CDEP participant)

The community vision at Wallaga Lake also includes re-establishing Umbarra as an art and cultural centre, hopefully with a commercial return. Progress is stalled, though, because enterprise development now falls to the already overstretched land council, which has neither the resources nor the staffing to develop a business plan. At Eden, the land council has successfully secured support to develop a major cultural tourism project through development of the Bundian Way. There, too, however, progress has been slowed by limited resources. According to project officer Les Kosez, closing CDEP has made it more difficult to get development projects off the ground and create employment opportunity:

If we had that [CDEP] program right now the development of the Bundian Way would be far more progressed ... Realistically we would have been in a position now where we could probably be moving boys completely off CDEP into sustainable employment with us where we are paying them from the generated income that we [would] have (in Brown 2015). 
One option might include reviving something like the Community Employment and Enterprise Development scheme that, under the Hawke Government, provided capital grants to establish small community enterprises (which tend to be overlooked by Indigenous Business Australia), as well as the Enterprise Support Units that provided management support and technical advice. Such a grants scheme might also offer support to community development activities and social enterprises that are not likely to generate significant income, such as for capital equipment and recurrent non-wage costs. Grants would need to be multiyear to ensure sustainability. With this approach, mainstream employment service providers could contribute a portion of their existing funding (allocated to assist jobseekers find work) to link these projects to formal training.

An appropriate policy response would necessitate much further consultation with local Koori communities, who are best placed to identify local needs. But if governments are serious about improving outcomes for Aboriginal people on the far south coast of NSW, this may go some way to redressing what remains an ongoing policy failure.

\section{References}

Aboriginal and Torres Strait Islander Social Justice Commissioner (2011). Social justice report 2011, Australian Human Rights Commission, Sydney.

ABS (Australian Bureau of Statistics) (2006). Census of population and housing, Australian Bureau of Statistics, Canberra.

ABS (Australian Bureau of Statistics) (2011). Census of population and housing, Australian Bureau of Statistics, Canberra.

Altman J (2007). Neo-paternalism and the destruction of CDEP, CAEPR Topical Issue No. 14/2007, caepr.anu.edu.au/sites/default/ files/Publications/topical/Altman_Paternalism.pdf.

Altman J \& Sanders W (1991). The CDEP scheme: administrative and policy issues. Australian Journal of Public Administration, 50(4), 515-25. 
Altman J \& Smith DE (1993). Compensating Australian 'losers': a community-oriented approach from the Aboriginal social policy arena, CAEPR Discussion Paper No. 47, Centre for Aboriginal Economic Policy Research, The Australian National University, Canberra.

Andrews K (2006a). CDEP 2006-07 to build on success, media release, 1 July.

Andrews K (2006b). Twice as many CDEP participants get jobs, media release, 20 October.

Andrews K (2006c). Indigenous employment discussion paper released, media release, 6 November.

ATSIC Office of Evaluation and Audit (Aboriginal and Torres Strait Islander Commission) (1997). Evaluation of the Community Development Employment Projects (CDEP) program: final report, ATSIC Office of Evaluation and Audit, Canberra.

Australian Government (1987a). Aboriginal employment development policy statement: policy paper no. 1, Australian Government Publishing Service, Canberra.

Australian Government (1987b). Aboriginal employment development policy: policy paper no. 3: community-based employment, enterprise and development strategies, Australian Government Publishing Service, Canberra.

Brough M (2006). Blueprint for action in Indigenous Affairs, speech by The Hon. Mal Brough MP, 5 December, Canberra.

Brown B (2015). South East Aboriginal communities are falling through the disadvantage gap, ABC South East NSW [online], 24 February, www.abc.net.au/local/stories/2015/02/24/4186054.htm.

Champion M (2002). Urban CDEPS as Indigenous employment centres: policy and community implications, CAEPR Discussion Paper No. 228, Centre for Aboriginal Economic Policy Research, The Australian National University, Canberra.

Chittick L \& Fox T (1997). Travelling with Percy: a south coast journey, Aboriginal Studies Press, Canberra. 
Cruse B, Stewart L \& Norman S (2005). Mutton fish: the surviving culture of Aboriginal people and abalone on the south coast of New South Wales, Aboriginal Studies Press, Canberra.

DEWR (Department of Employment and Workplace Relations) (2006). Indigenous potential meets economic opportunity, Discussion paper, Department of Employment and Workplace Relations, Canberra.

Donaldson SD (2006). Stories about the Eurobodalla by Aboriginal people: public report, stage two Eurobodalla Aboriginal cultural heritage study, Eurobodalla Shire Council, Moruya NSW.

Donaldson SD (2008). Aboriginal men \& women's heritage: Eurobodalla, Eurobodalla Shire Council, Moruya NSW.

Egloff B, Peterson N \& Wesson S (2005). Biamanga and Gulaga: Aboriginal cultural association with the Biamanga and Gulaga National Parks, Office of the Registrar, Aboriginal Land Rights Act 1983 (NSW), Sydney.

Evans C (2006). Cut to Indigenous employment services a backward step, media release, 6 November.

Feary S \& Donaldson S (2011). Connecting with Country in the Eurobodalla, south coast, New South Wales: exploring the connections between Aboriginal people, places and cultural practises, report prepared for Eurobodalla Shire Council and the Aboriginal community, www. esc.nsw.gov.au/living-in/about/culture-and-heritage/heritage-itemsand-places/Connecting_with_Country_Part_A.pdf.

Goulding M \& Waters K (2005). Eurobodalla Aboriginal cultural heritage study south coast New South Wales, Eurobodalla Shire Council, Moruya NSW.

Graham C (2012) 'White trash mixed with black blood': The truth about Toomelah, Chris Graham at large, chrisgrahamatlarge. com/2012/07/04/white-trash-mixed-with-black-blood-the-truthabout-toomelah/.

HRSCATSIA (House of Representatives Standing Committee on Aboriginal and Torres Strait Islander Affairs) (1992). Mainly urban: report of the inquiry into the needs of urban dwelling Aboriginal and Torres Strait Islander people. Australian Government Publishing Service, Canberra. 
Hunt J (2008). Between a rock and a hard place: self-determination, mainstreaming and Indigenous community governance. In Hunt J, Smith DE, Garling S \& Sanders W (eds), Contested governance: culture, power and institutions in Indigenous Australia, CAEPR Research Monograph No. 29, ANU E Press, Canberra.

Hunt J (2013). Looking after Country in New South Wales: implementing a Land \& Sea Country Plan on the far south coast, CAEPR Working Paper No. 90/2013, Centre for Aboriginal Economic Policy Research, The Australian National University, Canberra.

McKenna M (2002). Looking for Blackfella's Point: an Australian history of place, UNSW Press, Sydney.

Merrimans Local Aboriginal Land Council (2014). Merrimans Local Aboriginal Land Council Community Land and Business Plan 2014 - 2019, Merrimans Local Aboriginal Land Council, Wallaga Lake.

Midlam A (2011). A tale of three Missions, Online Opinion, 27 May, www.onlineopinion.com.au/view.asp?article $=12098 \&$ page $=0$.

Miller M (Chairman) (1985). Report of the Committee of Review of Aboriginal Employment and Training Programs, Australian Government Publishing Service, Canberra.

Neville I (2014). Labour market overview of the Far South Coast (Shoalhaven, Eurobodalla and Bega Valley Shire), Australian Government Department of Employment.

NSW Office of Environment and Heritage (2012). Aboriginal people living and working on the NSW coast: A historical review, NSW Office of Environment and Heritage, Sydney.

Redfern Residents for Reconciliation (2006). Submission to the 'Indigenous potential meets economic opportunity' discussion paper, www.redwatch.org.au/redw/cdep/061215rrr.

RCIADIC (Royal Commission into Aboriginal Deaths in Custody) (1991). Royal Commission into Aboriginal Deaths in Custody: National report volume 4. Australian Government Publishing Service, Canberra.

Rowse T (2001). The political dimensions of community development. In Morphy F \& Sanders W (eds), The Indigenous welfare economy and the CDEP scheme, CAEPR Research Monograph No. 20, ANU E Press, Canberra, 39-46. 
Rowse T (2002). Indigenous futures: choice and development for Aboriginal and Islander Australia, UNSW Press, Sydney.

Sanders W (2001). Adjusting balances: reshaping the CDEP scheme after 20 good years. In Morphy F \& Sanders W (eds), The Indigenous welfare economy and the CDEP scheme, ANU E Press, Canberra.

Smith B (1993). Unemployment income support, the active society and AEDP. Family Matters (35), 22-24.

Smith DE (1995). Redfern works: the policy and community challenges of an urban CDEP scheme, CAEPR Discussion Paper No. 99, Centre for Aboriginal Economic Policy Research, The Australian National University, Canberra.

Snowdon W (2006). CDEP changes: gutless approach, missed chances, media release, 6 November.

Spicer I (1997). Independent review of the Community Development Employment Projects (CDEP) scheme, Aboriginal and Torres Strait Islander Commission, Canberra.

Steering Committee for the Review of Government Service Provision (2009). Overcoming Indigenous disadvantage: key indicators 2009. Productivity Commission, Canberra.

Wesson S (2000). An historical atlas of the Aborigines of Eastern Victoria and Far South-Eastern New South Wales, Monash Publications in Geography and Environmental Science No. 53, Monash University, Melbourne.

Whitby T (2001). Reforming the CDEP scheme. In Morphy F \& Sanders $\mathrm{W}$ (eds), The Indigenous welfare economy and the CDEP scheme, ANU E Press, Canberra.

White J (2010). Peas, beans and riverbanks: seasonal picking and dependence in the Tuross Valley. In Keen I (ed.), Indigenous participation in Australian economies: historical and anthropological perspectives, ANU E Press, Canberra.

White J (2015). Reconstructing Aboriginal economy and society: The New South Wales South Coast at the threshold of colonisation. In Toner PG (ed.), Strings of connectedness: essays in honour of Ian Keen, ANU Press, Canberra. 
This text is taken from Better Than Welfare?: Work and livelihoods for Indigenous Australians after CDEP, edited Kirrily Jordan, published 2016 by ANU Press, The Australian National University, Canberra, Australia. 